DOI: 10.12731/2070-7568-2019-5-82-93

УДК 338.1

\title{
ВЛИЯНИЕ ЦИФРОВИЗАЦИИ ЭКОНОМИКИ НА УПРАВЛЕНИЕ ЗЕМЕЛЬНЫМИ РЕСУРСАМИ И ПРОВЕДЕНИЕ ТОРГОВ
}

Проскурина 3.Б.

За основу исследования взята одна из приоритетных направлений создание экосистемы циифровой экономики Российской Федеращии, где данные в циифровой форме являются ключевым критерием в недвижимости. Проведён анализ, результатов размещения информации о проведении продаж земельных участков на торгах используя методы статистического и аналитического исследования, анализа и синтеза данных. А также выявлены проблемы и представлены пути их решения.

Цель работы. Определение проблем управления и проведения продаж земельных участков на торгах в условиях влияния циифровой экономики.

Метод или методология проведения работы: в статье использовались аналитический и статистический методы анализа.

Результаты: сформулированы основные проблемы и представлены пути их решения при проведении торгов с земельными ресурсами в условиях ичифровизации экономики.

Область применения результатов: полученные результать рационально применять при проведении торгов с земельными ресурсами в условиях ичифровизации.

Ключевые слова: ицифровая экономика; земельный участок; аукциио; аренда; циирровые технологии; собственность.

\section{THE IMPACT OF THE DIGITALIZATION OF THE ECONOMY ON LAND MANAGEMENT AND TENDERING \\ Proskurina Z.B.}

The study is based on one of the priority areas for creating an ecosystem of the digital economy of the Russian Federation, where digital 
data is a key criterion in real estate. The analysis of the results of posting information on land sales at the auction using the methods of statistical and analytical research, analysis and data synthesis. It also identified problems and presented ways to solve them.

Objective. Definition of problems of management and carrying out of sales of the land plots at the auction in the conditions of influence of digital economy.

Method or methodology of the work: the article used analytical and statistical methods of analysis.

Results: the main problems are formulated and the ways of their solution in the course of bidding with land resources in the conditions of digitalization of the economy are presented.

Practical implications: the obtained results are rationally applied when bidding with land resources in the conditions of digitalization.

Keywords: digital economy; land plot; auction; rent; digital technology; own.

В Российской истории землеустройство занимает особое место, так как является главным механизмом для осуществления различных земельных преобразований. Государством определялась земельная политика по развитию землепользования страны, организовывалось планирование рационального использования и охраны земельных ресурсов страны, которые являются основой для жизни и деятельности всего народа [5, с. 132-137].

Целью анализа наиболее эффективного использования является определение варианта использования объекта оценки, обеспечивающего максимальную доходность [8, с. 179-182].

Приобретение земельного участка является хорошим способом вложения собственных средств, его можно использовать для различных видов деятельности, таких как: ведение сельского хозяйства, строительства, осуществление производства и др. Выгоднее всего приобретать участок из земель государственной или муниципальной собственности. В таких случаях покупатели сталкиваются с аукционами, по результатам которых определяется покупатель. 
Рынок недвижимости в настоящее время усиливает свои позиции, так как он позволяет генерировать большие доходы от приобретения и последующей продажи недвижимого имущества [4, с. 73-80].

Под аукционом в электронной форме (электронным аукционом) понимается аукцион, при котором информация о закупке сообщается заказчиком неограниченному кругу лиц путем размещения в единой информационной системе извещения о проведении такого аукциона и документации о нем, к участникам закупки предъявляются единые требования и дополнительные требования, проведение такого аукциона обеспечивается на электронной площадке ее оператором (ст.59 Ф3 «О контрактной системе в сфере закупок товаров, работ, услуг для обеспечения государственных и муниципальных нужд») [2].

Организацией аукционов, согласно Федеральному закону № 101Ф3 от 24.07.2002, занимаются органы местного самоуправления и государственной власти. Торги проводит учреждение, которое имеет лицензию на эту деятельность [3]. Организаторы торгов, в лице уполномоченных органов, устанавливают: время и место их проведения; сумму задатка; начальную цену; существенные условия договора.

Источники размещения информации об аукционе: официальный сайт по земельным торгам в РФ; сайт органа местного самоуправления; администрация. Информация об аукционах обязательно публикуется в местных СМИ - официальных печатных органах исполнительной власти, где также можно получить информацию о торгах.

Для участия в аукционе в электронной форме каждому участнику необходимо пройти процедуру аккредитации на ЭТП и оформить электронную цифровую подпись. А также заявители предоставляют следующие документы в соответствии с п. 1 ст.39.12 ЗК РФ [1]:

1) заявка на участие в аукционе по установленной в извещении о проведении аукциона форме с указанием банковских реквизитов счета для возврата задатка;

2) копии документов, удостоверяющих личность заявителя (для граждан); 
3) надлежащим образом заверенный перевод на русский язык документов о государственной регистрации юридического лица в соответствии с законодательством иностранного государства в случае, если заявителем является иностранное юридическое лицо;

4) документы, подтверждающие внесение задатка.

Участники подготавливают и вовремя подают пакет документов, начиная с даты начала срока о проведении торгов и заканчивая за 5 дней до даты проведения данного аукциона. Документы должны соответствовать формам и списку, которые указаны в той ЭТП, на которой принимается участие. Если же обнаружатся какие-то несоответствия, то участника ждет отказ в данном торге.

Торги могут не состояться по следующим причинам: подана только одна заявка или не подано ни одной заявки; аукционная комиссия приняла решение об отказе в допуске к участию всех участников; ни один участник не подал предложение о цене контракта; заказчик объявил об отказе о проведении торгов, его заявка на участие в аукционе будет аннулирована [1].

Раньше аукционы проводились лишь в традиционном формате, а именно: участники приходили на торги лично, либо направляли лиц по доверенности. Лицитатор объявлял был готов оплатить озвученную стоимость лота. Порядок проведения в настоящий момент не был изменен, появилась лишь его электронная форма. Отличие от традиционных торгов заключается в следующем: проводится в электронном формате посредством информационно-телекоммуникационной сети Интернет; для участия необходимо зарегистрировать личный кабинет; отсутствует необходимость лицитатора; правилами проведения аукциона в электронной форме установлено, что для идентификации и совершения юридически значимых действий необходимо иметь электронную цифровую подпись.

Всё это приводит к тому, что торги в электронной форме посредством Интернета дают возможность, не бегая по учреждениям выбрать подходящий лот, проанализировать его и сразу же отправить необходимые документы и заявку. 
Участник, который стал победителем аукциона, получает:

- заполненную в соответствии с требованиями организатора форму протокола аукциона по продаже земельного участка, в которой отображены его результаты;

- проект договора аренды или купли-продажи надела.

Организатору необходимо произвести расчет, а также разместить уведомление о результатах проведенных торгов в течение одного месяца. Данные сведения публикуются в тех же источниках, в которых был размещен сам лот о проведении торгов. Победитель аукциона оформляет в собственность земельный участок. Данная процедура осуществляется на основании постановления, которое издает глава муниципального образования. Продолжительность месяц с момента подписания данного протокола.

Заключение договора на продажу земельного участка и передача его в собственность другому лицу предусматривает то, что на заключительном этапе победитель торгов (покупатель) должен сам обратиться в регистрирующий орган и предоставить им необходимые для этого документы. Только после регистрации он становится полноправным владельцев надела. Эта же процедура касается и аренды земельных участков [11].

Рассмотрим основную информацию о проведении торгов на территории Российской Федерации в динамике. Диаграмма показатели проведения торгов на территории РФ за 2017-2019 гг. представлена на рис. 1 .

Из всех проанализированных лотов 33\% составляют лоты по аренде и продаже земельных участков. Как видно на диаграмме число данных лотов с годами уменьшается (на 12335 лотов). Однако это не означает то, что продажа и аренда земельных участков идет на спад. Рынок недвижимости, в том числе земельные участки, растет год за годом, а его востребованность никогда не упадет, так как строительство сейчас занимает огромную нишу в развитии регионов.

Можно заметить, что увеличивается количество лотов по продаже государственного и муниципального имущества, что также относится к недвижимости, и говорит нам о том, что данный рынок не упадет в цене и, конечно же, количестве. 


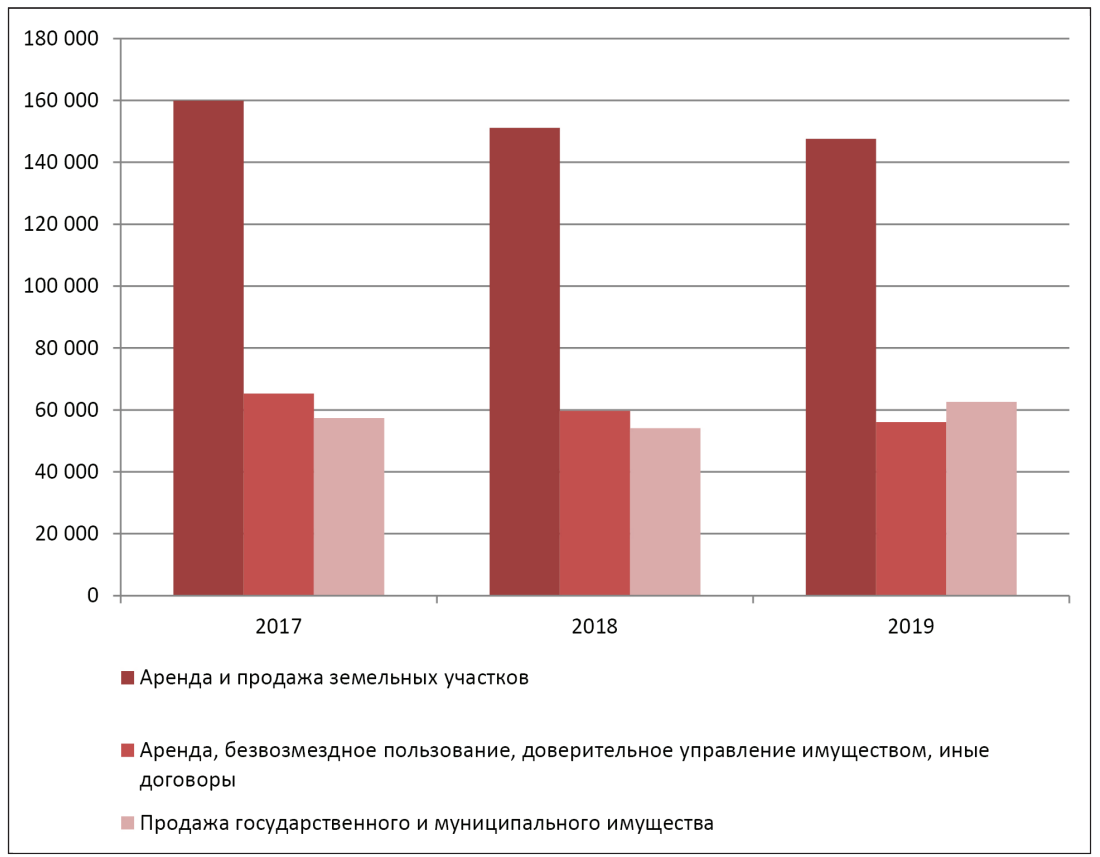

Рис. 1. Показатели проведения торгов на территории РФ за 2017-2019 гг.

Однако, не все объявленные торги завершаются и являются состоявшимися. От 10\% до 30\% торгов не состоятся или отменены. Это происходит по нескольким причинам: не подано ни одной заявки; единственный участник, который подал заявку; отклонены все заявки; участники, подавшие заявки, решили не принимать участие и др.

Информация о состоявшихся торгах в Москве и Московской области за 2017-2019 гг. представлена на рис. 2.

Анализируя рис. 2 можно увидеть, что количество продаж государственной и муниципальной собственности намного больше, чем аренды той же собственности. Несмотря на это, число арендованных помещений, зданий, земельных участков и иных объектов недвижимости с годами увеличивается. К примеру, с 2018 по 2019 года - это число увеличилось на 144,7\% (на 472 лота). А вот продажи участков упали по сравнению с 2018 годом на 40\% (на 1048 лота). 


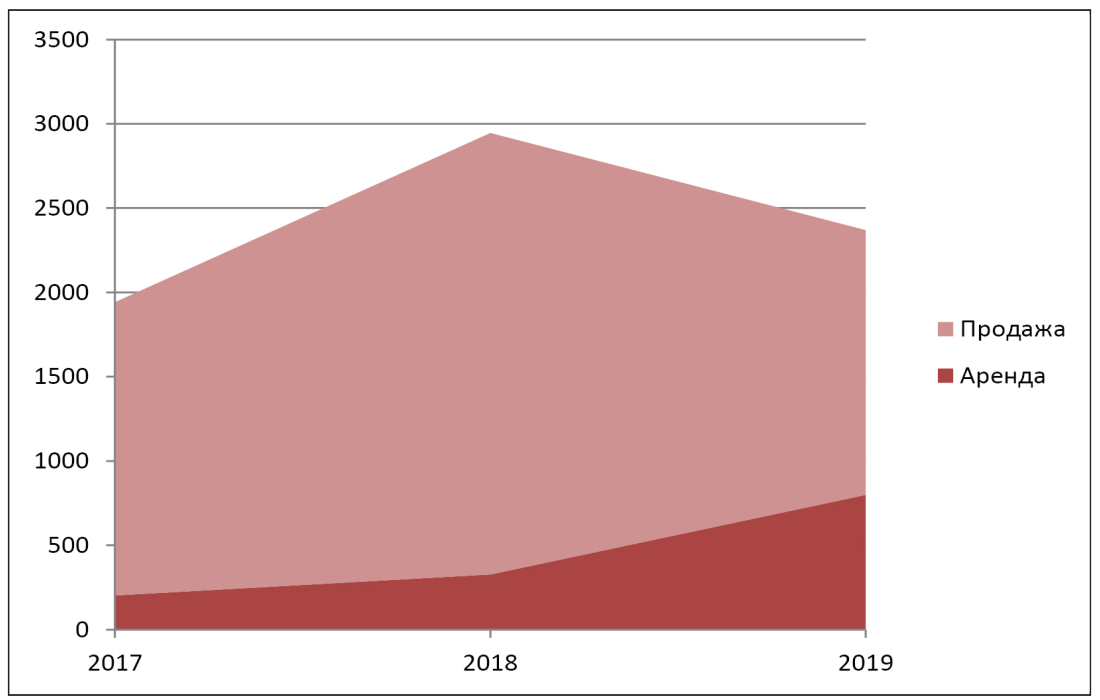

Рис. 2. Информация о состоявшихся торгах в Москве и Московской области за 2017-2019 гг.

Немаловажным компонентов торгов является начальная цена лотов, предоставляемых организациями. На рис. 3 можно увидеть, среднюю цену за лот по некоторым регионам России (Москва, Санкт-Петербург, Волгоградская область и Краснодарский край). По Москве и Волгоградской области за 2018-2019 гг. можно заметить, что цена сильно не колеблется. А вот по Санкт-Петербургу и Краснодарскому краю очень сильные колебания. В первом случае увеличение цены на 11 млн. руб., во втором случае уменьшение на 17 млн. руб.

Из рис. 3 видно, что данные колеблется и могут очень разниться в разных регионах в разные года.

Однако цифровая экономика при продаже земельных участках на торгах, будет увеличивать свои масштабы, так как является вполне удобным и быстрым способом заключения сделок и подачи заявок. Не нужно также открывать несколько сайтов одновременно, чтобы проверить определённые участки. Вся информация предоставляется на одном официальном сайте РФ, где можно подробно ее изучить. 


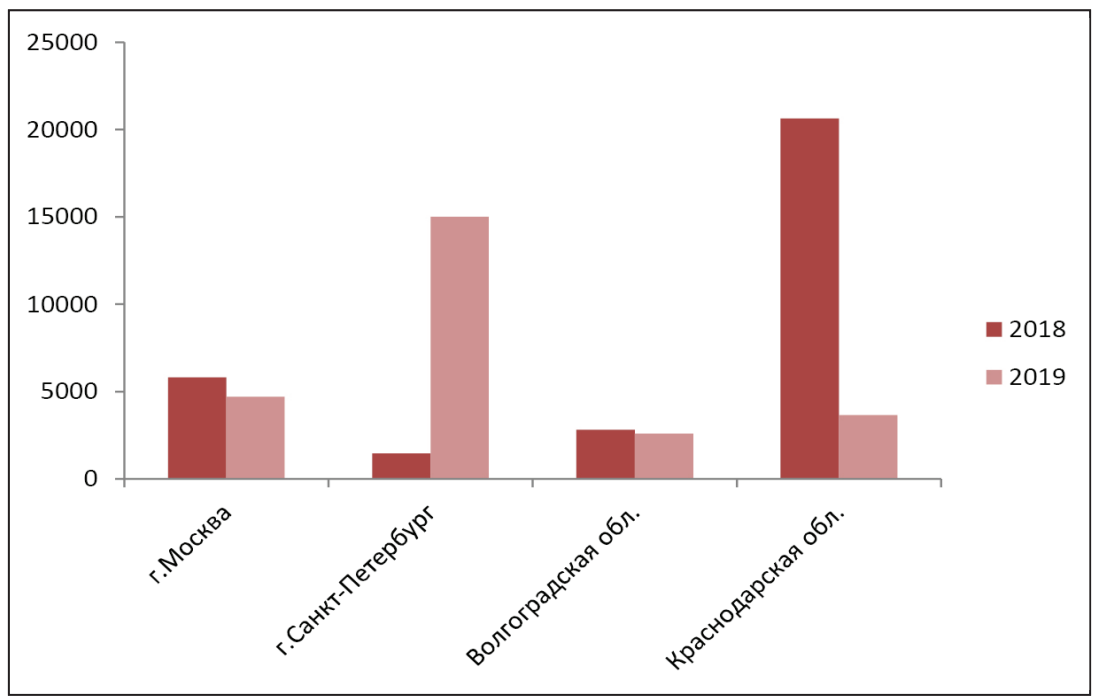

Рис. 3. Показатели средней стоимости лота в некоторых регионах РФ, тыс. руб.

Необходимо обратить внимание на то, что основное количество заключаемых сделок совершается в Москве и Санкт-Петербурге, то есть в городах, где быстрее растет экономика, развиваются цифровые технологии, лидирует наука. Для большего охвата количества совершаемых сделок и увеличения продаж государственной и муниципальной собственности нужно внедрять цифровые технологии на всей территории страны, изучать динамику спроса и предложения, а также другие показатели.

Магистральными направлениями государственного регулирования являются: сохранность территории и неприкосновенность; создание квалифицированного аппарата управления способную осуществлять единую политику управления, направленную на благо всего общества; повышение уровня жизни населения до уровня развитых стран; рационального использования и распределения природных богатств во благо всего населения страны; накопление и преумножение всех видов потенциала; создание условий для высокого уровня образования и здоровья нации; создание гуманных условий жизни и этики поведения и культуры [7, с. 237-240]. 
Регулирование мобильности производства подразумевает институциональное проектирование, для того чтобы создать независимые производственные сети и/или сервисные компании, разработчиков новых технологий и ноу-хау, компаний в сфере инженерии, связующие рыночные институты и потребителей, взаимодействующих друг с другом [6, с. 584-589].

Таким образом, влияние цифровой экономики на земельные участки при продаже их на торгах происходит в растущей динамике. Это положительно воздействует на экономику страны, на развитие предпринимательства и увеличения федерального бюджета. Нужно учитывать то, что система требует постоянного обновления, квалифицированного персонала, увеличения масштабов по всей стране, и что немало важно безопасности и защиты.

\section{Список литературы}

1. Земельный кодекс Российской Федерации от 25.10.2001 № 136-Ф3 (ред. от 02.08.2019). http://www.consultant.ru/document/cons_doc_ LAW_33773/ (дата обращения: 05.12.2019 г.).

2. Федеральный закон «О контрактной системе в сфере закупок товаров, работ, услуг для обеспечения государственных и муниципальных нужд» от 05.04.2013 № 44-Ф3. http://www. consultant.ru/document/cons_doc_LAW_144624/ (дата обращения: 02.12.2019 г.).

3. Федеральный закон «Об обороте земель сельскохозяйственного назначения» от 24.07.2002 № 101-Ф3. http://www.consultant.ru/ document/cons_doc_LAW_37816/(дата обращения: 02.12.2019 г.).

4. Макарова Е.Е., Мозолькова А.Е. Эффективность инвестиций в рынок недвижимости // Комплексное социально-экономическое и территориальное развитие Центрального федерального округа сборник научных трудов по материалам Всероссийской научно-практической конференции. 2019. С. 73-80.

5. Мирющенко Д.В. Состояние и перспективы развития землеустройства в современных условиях // Комплексное социально-экономическое и территориальное развитие Центрального федерального 
округа сборник научных трудов по материалам Всероссийской научно-практической конференции. 2019. С. 132-137.

6. Проскурина 3.Б., Макарова Е.Е. Доверительное управление имущественным комплексом как фактор инновационного развития экономики // Экономика и предпринимательство. 2018. № 8 (97). С. 584-589.

7. Проскурина 3.Б. Система функций государственного управления экономикой сферы зернопроизводства // Международные научные исследования. 2017. №2(31). С. 237-240.

8. Светлов А.В. Процесс анализа наиболее эффективного использования объекта недвижимого имущества // Комплексное социально-экономическое и территориальное развитие Центрального федерального округа сборник научных трудов по материалам Всероссийской научно-практической конференции. 2019. С. 179-182.

9. Аренда и продажа земельных участков. URL: http://utp.sberbank-ast. ru/ (дата обращения: 30.11.2019 г.).

10. Основные показатели по аукционам в Российской Федерации. URL: https://torgi.gov.ru/index.html (дата обращения: 30.11.2019 г.).

11. Продажа земельных участков через аукцион. https://pravovdom.ru/ zemlya/prodazha-zemelnyx-uchastkov-cherez-aukcion.html (дата обращения: 01.12.2019 г.).

\section{References}

1. Land code of the Russian Federation of 25.10.2001 № 136-FZ (as amended on 02.08.2019). http://www.consultant.ru/document/cons doc_LAW_33773/ (date accessed: 05.12.2019).

2. Federal law No. 44-FZ dated 05.04.2013 «On the contract system in the sphere of procurement of goods, works and services for state and municipal needs». http://www.consultant.ru/document/cons_doc_ LAW_144624/ (date accessed: 02.12.2019).

3. Federal law «On turnover of agricultural land» dated 24.07.2002 No. 101-FZ. http:/www.consultant.ru/document/cons_doc_LAW_37816/ (date accessed: 02.12.2019).

4. Makarova E.E., Mozolkova A.E. Effektivnost' investitsiy v rynok nedvizhimosti [Efficiency investments in the real estate market]. Komplek- 
snoe sotsial'no-ekonomicheskoe i territorial'noe razvitie Tsentral'nogo federal'nogo okruga sbornik nauchnykh trudov po materialam Vserossiyskoy nauchno-prakticheskoy konferentsii [Complex socio-economic and territorial development of the Central Federal district collection of scientific papers on the materials of the all-Russian scientific and practical conference]. 2019, pp. 73-80.

5. Miriushchenko D.V. Sostoyanie i perspektivy razvitiya zemleustroystva $\mathrm{v}$ sovremennykh usloviyakh [State and prospects of development of land management in modern conditions]. Kompleksnoe sotsial'no-ekonomicheskoe i territorial'noe razvitie Tsentral'nogo federal'nogo okruga sbornik nauchnykh trudov po materialam Vserossiyskoy nauchno-prakticheskoy konferentsii [Complex socio-economic and territorial development of the Central Federal district collection of scientific papers on the materials of the all-Russian scientific and practical conference]. 2019, pp. 132-137.

6. Proskurina Z.B., Makarova E.E. Doveritel'noe upravlenie imushchestvennym kompleksom kak faktor innovatsionnogo razvitiya ekonomiki [Trust management of the property complex as a factor of innovative development of the economy]. Ekonomika i predprinimatel'stvo [Economics and entrepreneurship]. 2018. No. 8 (97), pp. 584-589.

7. Proskurina Z.B. Sistema funktsiy gosudarstvennogo upravleniya ekonomikoy sfery zernoproizvodstva [System of functions of state management of the economy in the sphere of grain production]. Mezhdunarodnye nauchnye issledovaniya [Journal of international scientific researches]. 2017. No 2(31), pp. 237-240.

8. Svetlov A.V. Protsess analiza naibolee effektivnogo ispol'zovaniya obekta nedvizhimogo imushchestva [The process of analysis of the most effective use of real estate]. Kompleksnoe sotsial'no-ekonomicheskoe $i$ territorial'noe razvitie Tsentral'nogo federal'nogo okruga sbornik nauchnykh trudov po materialam Vserossiyskoy nauchno-prakticheskoy konferentsii [Complex socio-economic and territorial development of the Central Federal district collection of scientific papers on the materials of the all-Russian scientific and practical conference]. 2019, pp. 179-182.

9. Rent and sale of land. http://utp.sberbank-ast.ru/ (date accessed: 30.11.2019). 
10. Key indicators for auctions in the Russian Federation. https://torgi.gov. ru/index.html (date accessed: 30.11.2019).

11. Sale of land through auction. https://pravovdom.ru/zemlya/prodazha-zemelnyx-uchastkov-cherez-aukcion.html (accessed 01.12.2019).

\section{ДАННЫЕ ОБ АВТОРЕ}

Проскурина Зинаида Борисовна, доцент кафедры «Экономики и управления недвижимостью», кандидат экономических наук Российский государственный университет правосудия

ул. Новочеремушкинская, 69, г. Москва, 117418, Российская Федеращия

7365313@mail.ru

\section{DATA ABOUT THE AUTHOR}

Proskurina Zinaida Borisovna, associate professor «Economy and property management», Candidate of Economic Sciences Russian State University of Justice 69, Novocheremushkinskaya St., Moscow, 117418, Russian Federation

7365313@mail.ru

SPIN-code: 6012-4209 